\title{
For the right hemiliver graft may need tissue expander after living donor liver transplantation
}

\author{
Batsaikhan Bat-Erdene
}

Department of Surgery, Mongolian National University of Medical Science, Ulaanbaatar, Mongolia

Background: The number of liver transplantation (LT) increases last few years, which is related with populating the high surgical technology in developing country like in Mongolia. The main reason of LT is a hepatitis B virus-related liver cirrhosis in Mongolia. LT had started since 2011 under the support of Professor Sung Gyu Lee from hepatobiliary surgery and LT of Asan Medical Center. Veno-occlusive disease, Budd-Chiari syndrome, and congestive hepatopathy, all of which results in hepatic venous outflow obstruction (HVOO). The early HVOO is rare, however that could raise a serious complication as a graft failure and eventual lose. We report a case of early HVOO, which may result of size mismatch of abdominal cavity. Acute cellular rejection of liver allograft may influenced due to graft malposition, which unsized upper part of abdomen between donor and recipient after living donor LT. The size mismatch of body may produce kinking syndrome after right lobe living donor LT, which reveals the HVOO without anastomosis complication.

Methods: A 38-year-old male patient with liver cirrhosis due to hepatitis B virus, HDV, hepatocellular carcinoma in S8 of the liver (Child-Pugh score-B, Model For End-Stage Liver Disease-18). On the first postoperative day the patient developed impairment of the liver function. Doppler ultrasound showed the different speed of right hepatic vein preanastomosis and postanastomosis field. This was diagnosed acute liver failure due to veno-oclusive disease, after that started intensive therapy.

Results: Kinking or twisting of the venous anastomosis is related with anatomical mismatch between the graft and the recipient abdomen, even though transplanted the right hemiliver graft. HVOO results acute cellular rejection, which treated by pulse therapy. However it should be managed by surgically, put the tissue expander.

Conclusions: We report the right graft needs the tissue expander for mismatching between the graft and recipient abdomen.

Corresponding author: Batsaikhan Bat-Erdene

E-mail: Batsaikhan@mnums.edu.mn

\section{(c) The Korean Society for Transplantation}

This is an Open Access article distributed under the terms of the Creative Commons Attribution Non-Commercial License (http://creativecommons.org/licenses/by-nc/4.0/) which permits unrestricted non-commercial use, distribution, and reproduction in any medium, provided the original work is properly cited. 